\title{
The Ecosystem Approach in Ocean Planning and Governance: An Introduction
}

\author{
David Langlet and Rosemary Rayfuse
}

\section{1 \\ Introduction}

In theory, the need for an ecosystem approach to the management of natural resources seems almost intuitive. The management and regulation of human activities that affect species, ecosystems and natural processes should surely be based on scientific knowledge of the wider systems and interactions in which such species (including homo sapiens), ecosystems or processes are situated. Moreover, to be effective, management measures should surely be designed and continuously adapted with consideration to the scales and dynamics (including the lack of full understanding) of ecosystem characteristics and with the involvement of concerned stakeholders. Nevertheless, despite its apparently intuitive appeal, the ecosystem approach, as a management principle, is of fairly recent origin. The scientific ideas on which the ecosystem approach is premised can be traced at least to the first half of the 20 th century. ${ }^{1} \mathrm{How}^{-}$ ever, the approach only gained general recognition as a policy concept in 1995 when the parties to the Convention on Biological Diversity (СвD) agreed that the ecosystem approach 'should be the primary framework of action to be taken under the Convention'.2 According to a 'common understanding' adopted by those same parties, the ecosystem approach 'is a strategy for the integrated management of land, water and living resources that promotes conservation and sustainable use in an equitable way .... It 'requires adaptive management

1 R Edward Grumbine, 'What Is Ecosystem Management?' (1994) 8 Conservation Biology 27.

2 СвD, Decision II/8, Preliminary Considerations of Components of Biological Diversity Particularly under Threat and Action which could be taken under the Convention (Jakarta, 17 November 1995), para. 1. On earlier expressions of the ecosystem approach or 'ecosystems thinking' in international law and policy, see Arie Trouwborst, 'The Precautionary Principle and the Ecosystem Approach in International Law: Differences, Similarities and Linkages' (2009) 18 Review of European Community and International Environmental Law 26.

(C) DAVID LANGLET AND ROSEMARY RAYFUSE, 2019 | DOI:10.1163/9789004389984_002 This is an open access chapter distributed under the terms of the prevailing CC-BY-NC License at the time of publication. 
to deal with the complex and dynamic nature of ecosystems and the absence of complete knowledge or understanding of their functioning. 3

A few years later, the 12 so-called 'Malawi Principles for the Ecosystem Approach' were elaborated within the СвD framework and endorsed by the parties to the Convention. ${ }^{4}$ Among these principles is the recognition that management objectives are a matter of societal choice (Principle 1) and that the ecosystem approach should seek the appropriate balance between conservation and use of biodiversity (Principle 10). In terms of how management should be structured, the principles hold that the ecosystem approach should be undertaken at the appropriate scale (Principle 7) and that management should be decentralized to the lowest appropriate level (Principle 2). Ecosystems must be managed within the limits of their functioning (Principle 6), and while change is recognised as inevitable (Principle 9), objectives for ecosystem management should be set for the long term (Principle 8). In addition, application of the ecosystem approach should involve consideration of all forms of relevant information (Principle 11) and involve all relevant sectors of society and scientific disciplines (Principle 12).

In practice, the application of the ecosystem approach is anything but intuitive. The various, and varying, features and complexities of both natural ecosystems and human-created institutional, legal and administrative systems make the effective implementation of the ecosystem approach both complex and highly challenging. Given the vast number of complex issues to be considered in applying an ecosystem approach, it is difficult to stipulate universally applicable rules of any significant specificity for the effective operationalization of the approach. Nevertheless, despite these challenges, the approach is now well established as a guiding principle in many contexts and its application is often seen as a prerequisite for the successful management of ecological systems.

In the international law context, the ecosystem approach has come to feature particularly strongly in the context of marine management. One early iteration is found in Article II of the 1980 Convention on the Conservation of Antarctic Marine Living Resources, ${ }^{5}$ which requires any conservation or harvesting and associated activities to be carried out with regard not only to the maintenance of the ecological relationships between harvested and nonharvested species but also to the broader marine ecosystem as a whole. The

3 CBD, COP Decision v/6 Ecosystem Approach (Nairobi, 26 May 2000).

4 CBD, COP Decision VII/11 Ecosystem Approach (Kuala Lumpur, 9-20 and 27 February 2004).

5 Convention on the Conservation of Antarctic Marine Living Resources, Canberra, 20 May 1980 (into force 7 April 1982) (1982) 19 ILM 841. 
approach has also been endorsed by the parties to the Helsinki ${ }^{6}$ and OSPAR ${ }^{7}$ Conventions relating to the protection of the marine environment of the Baltic Sea and North East Atlantic, respectively ${ }^{8}$ and, at the global level, is deeply embedded in the 1995 United Nations Fish Stocks Agreement. ${ }^{9}$

In EU law, the Marine Strategy Framework Directive (MSFD) $)^{10}$ requires adaptive management on the basis of the ecosystem approach to be applied with the aim of attaining good environmental status and, according to the Directive on marine spatial planning (MSPD), ${ }_{11}^{11}$ an ecosystem-based approach will allow for an adaptive management which ensures refinement and further development as experience and knowledge increase. ${ }^{12}$ The EU Water Framework Directive (WFD) ${ }^{13}$ which has great significance for marine waters, in particular in coastal areas, is also functionally based on an ecosystem approach even though that exact terminology is not employed. In addition, the EU's common fisheries policy (CFP) aims to implement the ecosystem-based approach to fisheries management so as to ensure that negative impacts of fishing activities on the marine ecosystem are minimized. ${ }^{14}$

Although the definition and principles provided within the СBD regime remain a central articulation of the conceptual ideas underpinning 'ecosystemthinking', there is continued discussion of what precisely the requirements for

6 Convention on the Protection of the Marine Environment of the Baltic Sea Area, Helsinki, 9 April 1992 (into force 17 January 2000) (1992) 2099 UNTS 195.

7 Convention for the Protection of the Marine Environment of the North-East Atlantic, Paris, 22 September 1992 (into force 25 March 1998) (1993) 32 ILM 1075.

8 Record of the First Joint Ministerial Meeting of the Helsinki and ospar Commissions (Bremen, 26 June 2003) (OSPAR/HELCOM statement), Annex 5 ('Towards an Ecosystem Approach to the Management of Human Activities').

9 Agreement for the Implementation of the Provisions of the UN Convention on the Law of the Sea of 10 December 1982 relating to the Conservation and Management of Straddling Fish Stocks and Highly Migratory Fish Stocks, 4 August 1995 (into force 11 December 2001) 2167 UNTS 3.

10 Directive 2008/56/EC of the European Parliament and of the Council of 17 June 2008 establishing a framework for community action in the field of marine environmental policy (Marine Strategy Framework Directive) [2008] OJ L 164/19.

11 Directive 2014/89/EU of the European Parliament and of the Council of 23 July 2014 establishing a framework for maritime spatial planning [2014] OJ L257/135.

12 Directive 2008/56/EC (n 10), Art. 3(5) and Directive 2014/89/EU (n 11), preambular para. 14.

13 Directive 2000/6o/EC of the European Parliament and of the Council of 23 October 2000 establishing a framework for Community action in the field of water policy [2000] OJ L $327 / 1$.

14 Regulation (EU) No 1380/2013 of the European Parliament and of the Council of 11 December 2013 on the Common Fisheries Policy ... (2013) OJ L354/22, Art. 2(3). 
an ecosystem approach are. ${ }^{15}$ Most of the legal instruments cited above do not (clearly) define what is meant by such an approach. There are also a host of related concepts, such as ecosystem-based management (ЕвM) and the ecosystem approach to management (ESAM), which are sometimes used more or less interchangeably and at other times are ascribed more distinct meanings. ${ }^{16}$ However, while the significance of a distinct terminology should not be discounted, more pressing issues relate to the actual implementation of core features of the approach and what lessons can be learned from the experiences of implementation gained in various settings so far.

While a plethora of literature on the ecosystem approach already exists, this literature is largely written from a natural science perspective, ${ }^{17}$ or from the perspective of specific sectors, such as fishing. ${ }^{18}$ Analyses of the implications and applications of the approach in a marine context from a legal and policy perspective are more scare. ${ }^{19}$ Based on this recognition, this volume brings together a range of scholars, mostly but not exclusively from the legal and social sciences, to provide a thorough analysis of different manifestations of the ecosystem approach, including challenges encountered and potential ways to manage these challenges. The focus is predominantly a European one, both in a geographic sense and in terms of the law and policy that is analyzed. However, the analysis is augmented by adding perspectives from other jurisdictions, such as Kenya and the United States, thus allowing a more nuanced understanding of the particular characteristics of the implementation of the approach in Europe and of more universal challenges associated with the effective achievement of management based on the ecosystem approach. As discussed below, the chapters are grouped into three thematic parts followed by a concluding chapter which seeks to draw out the lessons learned.

15 For examples of various definitions, see Rachel D Long, Anthony Charles, Robert L Stephenson, 'Key principles of marine ecosystem-based management' (2015) 57 Marine Policy 53 .

16 See e.g. Sara Söderström and others, 'Environmental Governance' and 'Ecosystem Management': Avenues for Synergies between Two Approaches' (2016) 17 Interdisciplinary Environmental Review 1.

17 See e.g. David Waltner-Toews, James J Kay and Nina-Marie E Lister, The ecosystem approach: complexity, uncertainty, and managing for sustainability (Columbia University Press 2008).

18 See e.g. Villy Christensen and Jay Maclean (eds), Ecosystem approach to fisheries: a global perspective (Cambridge University Press, 2011).

19 See, however, Sue Kidd, Andy Plater and Chris Frid (eds), The Ecosystem Approach to Marine Planning and Management (Earthscan 2011), and Vito de Lucia, 'Competing Narratives and Complex Genealogies: The Ecosystem Approach in International Environmental Law' (2015) 27 Journal of Environmental Law 91-117. 
The chapters in Part I explore a number of cross-cutting issues and critical perspectives on the ecosystem approach. In particular, while an ecosystem approach has long been a central perspective in environmental management and policy, it is still relatively new to the legal setting. Initiatives aimed at creating flexible and dynamic legal instruments have become increasingly common but their interpretation and application has often been subject to criticism relating to the perceived tension between legal certainty, identified as a core tenet of (rule of law based) legal systems, and the flexibility and adaptivity espoused by the ecosystem approach. This potential conflict is examined, from different viewpoints, in the chapters by Niko Soininen and Froukje Platjouw and by Brita Bohman.

Soininen and Platjouw (Chapter 2) take as their starting point the fact that the three core EU directives relating to aquatic environments, the WFD, the MSFD and the MSPD, all embrace the ecosystem approach as a leading paradigm, either implicitly or explicitly. All three also prescribe what is often referred to as a programmatic approach, i.e. an approach that involves the adoption of cyclical and evolving plans and programmes as primary tools for attaining environmental goals. In this prescription the authors identify a fundamental assumption of continuous change as regards management measures and thus a need for the law to be adaptive. This need for adaptive management of socio-ecological systems is underpinned by the insight that human understanding of such systems is incomplete and constantly evolving. Inevitably, this raises questions about what adaptive law should look like in practise and how such law may be reconciled with traditional features of law, such as legal certainty.

Against this background, Soininen and Platjouw explore the linkages between resilience, adaptivity and the rule of law and establish criteria for a systematic and analytic review of regulatory resilience. On that basis, they assess the regulatory design of the three EU directives to identify possible shortcomings of the programmatic approach in achieving an ecosystem approach, and they propose alterations to the legal frameworks in question. Their analysis reveals that while legal certainty may sometimes act as a hindrance to adaptivity, in other circumstances it can serve as a crucial mechanism for driving environmentally friendly adaptive changes to social and economic practices. The authors emphasise that, as a concept, adaptive law is neutral in the sense that it sometimes furthers the cause of the environmentalist and at other times the interests of industry. The actual outcome of adaptive mechanisms will ultimately be decided by policy choices made in the design of regulatory goals 
and tools, and by scientific understanding of the socio-ecological systems. The authors find that all three directives possess the substantive capacity to support socio-ecological resilience. However, they note that coherence between the directives could be significantly improved and that the discretion of Member States to balance different substantive goals is sometimes too broad.

Taking the regulation of eutrophication in the Baltic Sea as her object of investigation, Bohman (Chapter 3) assesses the extent and manner in which different aspects of the ecosystem approach can be identified in the regulatory regime established primarily by the regional 1992 Convention on the Protection of the Marine Environment of the Baltic Sea Area (Helsinki Convention) with its governing body HELCOM and the main marine related directives of the EU. According to Bohman, the ecosystem approach has become the base for a gradual and perceptible evolution of new normative tools in this regime, shaping the way law is interpreted and applied. Nevertheless, even though many of the features that typically represent an ecosystem approach are reflected in the current regulatory setting for the Baltic Sea, the vagueness and flexibility of their expression in the positive law leaves considerable leeway to States in deciding on specific measures to be adopted. Still, Bohman finds that the concept of the ecosystem approach promotes new ways of applying core environmental law principles, in ways that are better adjusted to complex environmental problems. Not only does the implementation of such features lead to a more ecosystem-focused regulatory system, it might also facilitate more effective implementation of regulatory requirements - even where traditional compliance mechanisms are lacking. Bohman points to the development of a process for making ecosystem assessments at different levels and identifying what kind of regulatory actions might lead to the desired result as perhaps the most important effect of the uptake of the ecosystem approach in the regional regulation of eutrophication. She describes this as enabling a 'managerial compliance' process that seems to bridge many of the uncertainties arising from the regulatory structure and the complex environmental factors it seeks to address. However, time-lags between measures taken and visible results, and in the adoption of effective operational targets, offer real challenges even with such a system in place.

In his contribution, Aron Westholm (Chapter 4) addresses the spatial dimension of the ecosystem approach from the understanding that marine management is, to a large extent, a question of delimiting the ocean into smaller, more manageable, units. As stipulated by Principles 2 and 7 of the Malawi Principles, the ecosystem approach requires management to be 'decentralised to the lowest appropriate level' and 'be undertaken at the appropriate spatial and temporal scales'. This inevitably raises questions as to the appropriate geographic 
delimitations, in terms of ecosystem functionality, and the appropriate management level within the administrative system for such governance.

Using a theoretical framework grounded in legal geography, and with the transposition of the WFD, the MSFD, and the MSPD in Sweden as examples, Westholm examines the way in which choices of management levels and geographical scales affect the functional application of the ecosystem approach. This in turn enables an assessment of whether there is a coherent definition of an ecosystem approach within EU marine legislation. He makes clear the importance of choices of scale and level by demonstrating that the choice of scale of what is to be governed inevitably entails sacrifices, either in detail, or in how much of a particular marine ecosystem may actually be captured by the governance regime. Westholm identifies similar effects associated with both the choice of management level and of the administrative body that is tasked with performing the management. As he notes, when legal frameworks fail to provide clear or consistent guidance on the scale and level of the management of ecosystems, the nature or content of the management is also likely to differ. Such discrepancies challenge the coordination of efforts, both within and between States, which is essential to the governance of complex and interconnected ecosystems.

Of course, different types of interactions between land and sea have influenced human activity on land as well as at sea since ancient times. Indeed, modern science now shows us how land-sea interaction (LSI) involves both natural processes across the land-sea interface and the interrelationships between human activities in this zone. Against this evolving knowledge, Sue Kidd (Chapter 5) explores the connection between LSI and ocean planning and governance arrangements premised on the ecosystem approach prompted by the EU's MSP Directive. Focusing on what this connection might mean for landward communities and for governance of the land, she identifies a range of options and examples for institutional and legislative arrangements to address LSI and shows how LSI can be addressed in a variety of ways and at a variety of scales of governance. As she notes, consideration of how to effectively address LSI has influenced the recent evolution of ocean governance arrangements at various levels. Nevertheless, when analysing the current situation on the basis of principles for an ecosystem approach, significant ocean governance related challenges may be identified. These challenges call for further innovation in approaches to governance to address LSI issues and to respond to the integrated management of land, water, and living resources required by the ecosystem approach. According to Kidd, the introduction of new systems of MSP heralds an era of governance experimentation that is not only focussed on the ocean but also prompts change in established patterns of governance of the 
land. Importantly, however, basic levels of understanding are needed for wide and meaningful engagement to take place and for society to make informed choices regarding environmental trade-offs. This brings to the fore the notion of ocean literacy which, as Kidd explains, is concerned with promoting behavioural change not only at an individual level but also at a societal level.

In their contribution, Michael Gilek, Fred Saunders, and Ignè Stalmokaitè (Chapter 6) focus on the role of the ecosystem approach in marine spatial planning and its relationship to sustainable development. Having noted the relative paucity of aspects of social sustainability in the literature on MSP, they develop an analytical framework to explore how different ecosystem approach-practices reflect differing conceptions of sustainable development. The authors argue that, in concrete situations, it is not possible to give equal priority to all aspects of sustainable development, and that to understand how these aspects are weighted in marine spatial planning, insights must be gained into institutional arrangements and how policy goals are identified and negotiated. The authors explore the utility of their framework through three distinct case studies illustrating different MSP contexts in the Baltic Sea region. In each of the case studies, the analysis focusses on stakeholder and knowledge integration, i.e. important aspects of social sustainability. The case studies demonstrate that ecosystem approach principles for MSP developed at the international level and in some national MSP settings acknowledge a wide definition of the ecosystem approach. However, looking more closely at MSP practices, a significant gap is revealed between espoused principles and the practical implementation of the approach, especially regarding social aspects of sustainability such as participation, social inclusion and knowledge pluralism. While seeing possibilities for enhancing social inclusion and knowledge pluralism in ecosystem approach and MSP processes by developing more detailed guidance and requirements the authors see that as difficult to achieve in the short term. As an alternative, they suggest the possibility of developing a parallel and complementary 'Socio-cultural Approach' (SA) which would focus on how issues such as participation, procedural justice, social inclusion and knowledge pluralism could be promoted in MSP.

Turning to a different aspect of the role of humans in the ecosystem approach, an important element of the ecosystem approach, reflected in the guidelines on the ecosystem approach adopted by the parties to the $\mathrm{CBD},{ }^{20}$ is that humans are seen and treated as part of the ecosystem. In the final chapter

20 Convention Biological Diversity, Rio de Janeiro, 5 June 1992 (into force 29 December 1993) (1992) 31 ILM 822. 
in this Part, Kees Bastmeijer (Chapter 7) explores what this recognition may mean for implementing the ecosystem approach in marine planning by examining the protection regime set up by the EU Birds Directive and the Habitats Directive - known as Natura 2000 - and its implementation. The Natura 2000 regime applies to both terrestrial and marine ecosystems, although as Bastmeijer notes, comparatively few marine sites have been identified to date. Nevertheless, particularly when compared to the more recently adopted MSFD, much experience has been gained from the implementation of the Natura 2000 regime, particularly in the context of legal debates focused on the relationship between human ambitions and effective protection of nature. Drawing on implementation practice from The Netherlands, Bastmeijer explores the legal nature of the Natura 2000 regime and various attempts that have been made to undermine its protective capacity in the name of economic necessity.

As Bastmeijer notes, the Natura 2000 regime is not explicitly based on the ecosystem approach. Nevertheless, the regime leaves considerable space for this approach to be applied implicitly, and he demonstrates how the characteristics of an ecosystem-based approach connect well with the requirements of the Natura 2000 regime. In doing so he demonstrates how Natura 2000 may also play an important role in implementing ecosystem-based management in the marine environment. Importantly, Bastmeijer notes that EU legislation relating to the protection of the marine environment appears to allow for more explicit balancing of interests compared to Natura 2000 and he cautions against the risk of giving 'humans' too dominant a position in the ecosystem, thereby potentially undermining the effectiveness of an ecosystem-based approach. As he notes, in practice, the notion that humans are considered part of the ecosystem can easily become an excuse for its over-exploitation. In order to remedy this situation, and in view of experiences with the Natura 2000 regime, he calls for implementation of the MSFD to be based on a solid scientific definition of 'good environmental status' and that social and economic interests should not be permitted to compromise this definition. Rather, the achievement or maintenance of such status should be seen as constituting the very fundament of implementation efforts.

\section{Participation and Collaboration}

Public participation and stakeholder engagement and collaboration have been identified as core tenets of the ecosystem approach in ocean governance, not least due to their contribution to acceptance, ownership and support for management measures. The chapters in Part II of the book examine various aspects 
of the evolution, impact and practical implementation of public participation in ocean governance.

In her contribution, Antonia Zervaki (Chapter 8) examines the issue of public participation in the context of MSP. Initially introduced strictly for environmental management, MSP has undergone a gradual shift towards a more comprehensive perception of the spatial allocation of human activities and natural processes. It has evolved into a multipurpose organizational framework, founded on the ecosystem-based approach, aiming at the comprehensive management of different and often conflicting uses and processes relating to marine space. Zervaki assesses the evolution of the normative premises of MSP public participation based on an analysis of the relevant acquis of international institutions and the experience of certain national and sub-regional MSP ventures in the EU. She traces the development of public participation in MSP from an international soft law framework to regulation at the regional level and then engages in an assessment of actual practice of MSP public participation focusing on the experience of EU member states and MSP cooperation among national authorities and/or stakeholders at the sub-regional level. Based on this analysis Zervaki shows that, although originating from the sphere of environmental protection, public involvement in MSP, in line with the ecosystem approach, contributes to a wider shift in maritime governance from a traditional (inter)governmental logic to one where management of ocean affairs naturally involves actors such as international organizations, advocacy groups, ocean users and individuals. Further linking MSP to the UN sustainable development goals could promote public participation in MSP moving from consensus-seeking to the creation of multi-stakeholder partnerships in line with Sustainable Development Goal 17 on the revitalization of the global partnership for sustainable development.

Anne-Michelle Slater and Alison MacDonald (Chapter 9) let us follow the execution of and insights gained from an elaborate exercise in participatory decision-making relating to MSP in Scotland. The Cooperative Participatory Evaluation of Renewable Technologies on Ecosystem Services (CORPORATES) Project, was carried out by an interdisciplinary research group in order to provide a decision-making framework that would balance socio-economic and ecological issues. It combined the growing body of academic thought and policy work concerning implementation of the ecosystem approach with people having direct experience and knowledge of the local marine environment in order to develop a process for implementing the ecosystem approach in marine planning decisions. The aims of the project were to clarify whether a process could be developed that linked ecosystem services with MSP; to examine how the role of the law could be maximised to enable and enhance the 
development and implementation of the process; and to assess whether such a process could increase acceptance and understanding by all stakeholders in decisions relating to the location of large scale Marine Renewable Energy installations. As part of the process both the research team and the stakeholder participants gained insights into the role of law in the participatory process which influenced the design of the process as well as the researchers' conclusions.

One clear conclusion was that the implementation of such collaborative processes can build greater and shared understandings of the ecological and policy linkages and interactions and that deliberative techniques can reduce conflicts and facilitate planning. Another valuable insight was that although MSP itself is often regarded as a holistic process, effective planning and decision making in the marine environment require consideration of a comprehensive context beyond MSP legislation and policy. Interestingly, contrary to what had been expected, the existing legislative and policy framework was found to provide sufficient support for the decision-making process and to support the implementation of an ecosystem approach, provided that the law was understood and fully embedded into the participatory process.

\section{4}

\section{Thematic and National Perspectives and Experiences}

The chapters in Part 3 of this book examine a number of experiences in implementing the ecosystem approach in practice at the sectoral and national level. As the human activity that perhaps most immediately and strongly impacts marine ecosystems, fishing is an inevitable theme for any attempt to apply a comprehensive ecosystem approach to marine governance. At the same time, it has long seemed an almost intractable challenge to submit fishing policy and practice to such conditions as to make it compatible with diverse and healthy marine ecosystems. In her contribution Jill Wakefield (Chapter 10) queries why, despite being explicitly required, ecosystem-based management has failed to find traction under the EU's common fisheries policy (CFP) and why achieving good environmental status for EU waters, as currently defined, may not render EU seas resilient and productive.

Despite the serious state of many fisheries and their associated ecosystems, and the recurring revisions of the CFP, Wakefield identifies a severe disjuncture between EU policy on fishing and on the environment. The historical legacy of fisheries regulation in the EU having developed from and been imbued with the logic of agricultural policy, has resulted in a policy that is ill equipped to deal with the challenges of what is - unlike agriculture - essentially an 
extractive industry. While the conservation of fish and other marine biological resources within the frame of fisheries policy is under the exclusive competence of the $\mathrm{EU}$, the Union has failed to achieve a consistent approach to marine management and conservation. Although the environmental objectives of the MSFD are dependent on fisheries being conducted in a manner consistent with achieving good environmental status by 2020, there is no formal requirement to this effect, and in practice the MSFD has very limited impact on fisheries policy. Wakefield concludes that achieving both economically and environmentally viable fisheries will require subjecting the CFP to the terms of the MSFD and making extractors pay the full cost for the use of the marine living resources.

Eva Schachtner (Chapter 11) provides an in-depth assessment of the implementation and operationalisation of the ecosystem approach in Germany, one of the largest and most influential EU member states. Her focus is on the extent to which the German legal provisions for marine spatial planning and the spatial plans adopted for the German EEZ correspond to the requirements of the ecosystem approach. She finds that, to a large extent, the legal provisions and the plan are consistent, although there is still considerable scope for improvement with regard to the outcome of the planning process in terms of the content of the actual spatial plans. Taking a more forward-looking perspective, Schachtner also explores the potential of the current legal framework to achieve improved environmental protection in the forthcoming, second generation of spatial plans, by assessing whether the spatial planning tools are flexible enough to reflect the characteristics of ecosystems and whether further components need to be added to these tools.

As a basis for her assessment, Schachtner makes use of the 2016 Guideline for the implementation of ecosystem-based approach in Maritime Spatial Planning adopted by HELCOM and VASAB,${ }^{21}$ which constitute a recent compilation of elements of the ecosystem approach. In line with Westholm's analysis in Chapter 4, she identifies the distribution of MSP competences spatially and between public agencies as a potential threat to the holistic management required by the ecosystem approach. In particular, while EU law expects Member States to ensure protection of the environment as well as promote the sustainable development of various uses including energy generation, maritime transport, fisheries and aquaculture, the balancing of these different objectives in the MSP framework is largely left to the Member States.

21 VASAB is an intergovernmental multilateral co-operation of 11 countries in the Baltic Sea Region in spatial planning and development, see further http://www.vasab.org/index .php/about-vasab accessed 15 January 2018. 
Schachtner thus notes that the degree of progress towards ecosystem protection in Germany, as in other Member States hinges on the political will to see marine spatial planning not merely as a coordinating mechanism, but as an instrument for effectively implementing ecosystem-based management.

In his contribution, David Fluharty (Chapter 12) puts application of ecosystem approach in Europe in a comparative light through a vivid account for the complex manifestations of ecosystem based marine management in the United States. In contrast to the EU, where the ecosystem approach is introduced in a top-down fashion through the implementation of marine directives, the situation in the US is much more heterogeneous with a variety of approaches that collectively cover the main topics of the EU Directives while leaving much regional autonomy in terms of policy implementation. Fluharty identifies five principal and partly distinct approaches to achieving ecosystembased ocean management which are being pursued in the US, four of which are further examined in the chapter. This diversity is reflective of the absence of a clear or formally defined view of what marine ecosystem-based management is to achieve and results in uncoordinated and sometimes competitive processes.

As Fluharty's review of the evolution of marine policy in the US reveals, much more is known about marine ecosystems than is being applied when making management decisions. In addition, there is continuing resistance against allowing ecosystem-based management to play an effective role in assessing trade-offs between competing interests. In practice, there is little recognition of the fact that all ocean activities take place in an ecosystem context. At the same time, Fluharty finds that the combined effect of various laws and policies does form a foundation, although a fragmented one, on which ecosystem-based management approaches can build. He notes that the appetite in the US Congress for comprehensive, ecosystem based marine management-oriented legislation appears to be very small. Thus, given the absence of sufficient public and political support for consolidating the legal basis for a more comprehensive policy, the extent to which the US will have an ecosystem approach to marine management is likely, for the foreseeable future, to remain the cumulative effect of multiple stands of policy and implementation.

As a further outlook beyond Europe, and as a concrete illustration of landsea interaction and the significance of land policy for the marine environment, Collins Odote (Chapter 13) uses wetlands as a lens to assess the application of the ecosystem approach to coastal areas and ecosystems in Kenya. Tracing the causes of the rapid loss and degradation of wetlands to the fact that it is only recently that their value for society has been recognized, Odote notes that for a long time their main perceived utility lay in their potential for conversion 
to farmland. Drawing on the Malawi Principles as well as the ecosystem wide approach taken by the Convention on Wetlands of International Importance especially as Waterfowl Habitat (Ramsar Convention), ${ }^{22}$ Odote explores the legal preconditions for effective protection of coastal wetlands. He explains that, since 2013, Kenya has had an Integrated Coastal Zone Management Policy, but that much remains to be done to fully move from a single species approach to one that is inclusive, integrated and adaptive in line with the requirements of the ecosystem approach. The management process, which in view of the complexity of the challenge must be incremental and collaborative in nature, also needs to better align planning processes and structures to the linkages between land and water.

\section{5}

\section{Conclusion and Outlook}

In Part 4 of the book, David Langlet and Rosemary Rayfuse (Chapter 14) draw on the different perspectives and experiences provided in the preceding chapters in order to identify common themes and challenges as well as distinctive features of the understanding and operationalization of the ecosystem approach in different substantive fields and in different jurisdictions. The chapter highlights important insights and points to remaining challenges that require further work in terms of practical implementation as well as research.

22 Convention on Wetlands of International Importance especially as Waterfowl Habitat, Ramsar, 2 February 1971 (into force 21 December 1975) (1972) 11 ILM 969. 